\title{
QUALIDADE DE PERIÓDICOS CIENTÍFICOS ELETRÔNICOS BRASILEIROS QUE UTILIZAM O SISTEMA ELETRÔNICO DE EDITORAÇÃO DE REVISTAS (SEER)
}

\section{LA CALIDAD DE LAS REVISTAS BRASILEÑAS QUE UTILIZAN EL SISTEMA ELECTRÓNICO DE EDICIÓN DE REVISTAS (SEER)}

\author{
Sely Maria de Souza Costa - selmar@unb.br \\ Doutora em Ciência da Informação \\ Professora do Programa de Pós-Graduação em Ciência da Informação, \\ Universidade de Brasília, UnB
}

Luisa Veras de Sandes Guimarães - luisa.unb@gmail.com Bacharel em Biblioteconomia, Universidade de Brasília, UnB

\section{Resumo}

Este estudo objetiva avaliar em que medida títulos brasileiros que utilizam o Sistema Eletrônico de Editoração de Revistas (SEER) atendem aos requisitos de qualidade necessários a periódicos científicos. O universo da pesquisa consistiu de 303 títulos, do qual foi analisada amostra aleatória estratificada de 16 deles, cerca de $5 \%$ do total. Foram analisadas informações relativas à formação dos conselhos editoriais, políticas editoriais e processo de editoração, assim como o perfil dos autores. A conclusão geral é que os títulos estudados atendem apenas parcialmente aos requisitos de qualidade normalmente indicados para que uma revista seja considerada científica.

\section{Palavras-chave}

Periódico científico eletrônico. Acesso Aberto à literatura científica. Sistema Eletrônico de Editoração de Revistas (SEER). Qualidade de periódicos.

\section{INTRODUÇÃO}

Um dos canais mais utilizados para a comunicação científica é o periódico. Segundo Meadows (1999), o principal motivo para seu surgimento foi a necessidade de comunicação mais eficiente entre os pesquisadores. Tenopir e King (2001) mostram que artigos publicados em periódicos constituem o mais 
importante recurso informacional utilizado por cientistas em seu trabalho, tanto na atividade de docência quanto na de pesquisa.

É importante observar que, para os resultados do trabalho de pesquisa serem considerados como conhecimento científico, estes são avaliados por pares e, posteriormente, publicados num periódico / revista científica ou livro. No entanto, no que concerne aos títulos de periódicos, o valor de assinatura aumentou substancialmente ao longo das últimas décadas e o orçamento de grande maioria das bibliotecas, não. Isto impossibilitou as bibliotecas de manterem o mesmo número de assinaturas e, por conseguinte, criou uma barreira de acesso aos conteúdos de conhecimentos divulgados (KING; TENOPIR, 1998).

Tal contexto coincide com o avanço das tecnologias de informação e de comunicação (TIC), na segunda metade do século XX. Começam a surgir títulos eletrônicos, que tornam a publicação dos resultados de pesquisas mais ágil e dinâmica. Um dos impactos mais recentes das TIC na comunicação científica está relacionado à questão do Acesso Aberto a essa literatura.

Alberts (2002) salienta que, como as pesquisas científicas são financiadas basicamente com recursos públicos, seus resultados (o conhecimento científico recém-gerado) devem ser reconhecidos como bem público global e, portanto, devem estar livremente acessível a todos. Importante iniciativa brasileira visando ao Acesso Aberto foi a adoção, por parte do Instituto Brasileiro de Informação em Ciência e Tecnologia (lbict), do Sistema Eletrônico de Editoração de Revistas (SEER). Este é a customização do software Open Journal Systems (OJS) do Public Knowledge Project da University of British Columbia (Canadá) e objetiva a construção e o gerenciamento de todas as etapas de editoração de uma revista eletrônica (MÁRDERO ARELLANO; SANTOS; FONSECA, 2005).

Diante do exposto, a pergunta que esta pesquisa visa responder é:

A qualidade de periódicos científicos brasileiros que utilizam o SEER corresponde aos critérios que devem ser levados em consideração na criação e na manutenção de periódicos científicos eletrônicos?

Sua relevância reside no potencial de criação de conhecimento em área pouco explorada na literatura e por oferecer sugestões que podem servir de base para alterar políticas de editoração de periódicos científicos no Brasil. $O$ desenvolvimento das TIC permitiu a criação de significativo número de periódicos eletrônicos, sendo estes preferidos por muitos cientistas devido à agilidade na publicação e à abrangência maior. O uso do SEER no Brasil, por parte, principalmente, de instituições acadêmicas, para a criação e a manutenção de periódicos científicos eletrônicos, até março de 2008, permitira a criação de mais de 300 títulos. No entanto, quantidade não significa qualidade. Segundo Ferreira (2005), para o periódico adquirir caráter científico é preciso que siga rigoroso sistema de certificação de qualidade. A autora se refere não somente à qualidade do conteúdo publicado (o que garante seu mérito), mas também a aspectos variados referentes ao processo de editoração. 


\section{FUNDAMENTAÇÃO TEÓRICA}

\subsection{Tecnologias de informação e de comunicação e periódicos científicos}

As TIC desenvolveram-se na segunda metade do século $\mathrm{XX}$, no contexto da chamada explosão informacional. Com o passar do tempo, a comunicação eletrônica passou a ser amplamente utilizada por pesquisadores para disseminação de suas pesquisas, graças à rapidez e à possibilidade de interatividade. Garvey e Grifith (1979) empreenderam estudo com pesquisadores da área de Psicologia e apresentaram um modelo de comunicação científica para a área, baseado no meio impresso. A proposta apresenta o processo que envolve a comunicação científica, desde o início da pesquisa, passando pela apresentação dos resultados em conferências, pelo envio para avaliação, pela publicação e, finalmente, a utilização dos resultados.

Com o surgimento do suporte eletrônico, o modelo de Garvey e Grifith sofreu adaptações. Hurd (1996) efetivou estudo com cientistas naturais e apresentou um modelo inteiramente baseado no meio eletrônico. Percebe-se, no modelo da autora, que o tempo despendido nas etapas entre o início da pesquisa e a publicação e disseminação dos resultados diminui consideravelmente. Costa (1999), ao estudar os cientistas sociais, adaptou o trabalho de Hurd (1996) e propôs um arquétipo híbrido para a comunicação, em que meio impresso e meio eletrônico coexistem. Readaptando seu modelo, posteriormente, Costa (2006) apresentou nova versão, na qual procura representar o momento atual e mostrar o quanto meio impresso e meio eletrônico estão presentes em cada etapa da comunicação científica.

Para a autora ora citada, apesar das mudanças na comunicação científica, duas questões permanecem inalteradas. A primeira é a predominância do meio eletrônico nas etapas do processo em que a comunicação informal ocorre. A segunda é a tendência de cientistas das áreas exatas e naturais utilizarem mais a comunicação por meio eletrônico do que os cientistas sociais e humanistas. Moreno e Márdero Arellano (2005) acrescentam que a comunicação eletrônica permite a transmissão de conhecimentos de forma ágil, a baixo custo e com a possibilidade de maior interação entre os pesquisadores. No contexto atual, as questões mais discutidas sobre as TIC na comunicação científica dizem respeito aos Arquivos Abertos, os quais têm modificado significativamente a publicação científica.

Lagoze e Van de Sompel (2001) explicam que, na expressão Arquivo Aberto, a palavra arquivo é utilizada em sentido mais amplo, significando um repositório para armazenar informações. A palavra aberto, por seu turno, referese à arquitetura do sistema, o qual promove uma interface de máquina que facilita a disponibilidade de conteúdos de diversos fornecedores. A origem dos Arquivos Abertos está associada a problemas e insatisfações com o sistema de publicação científica tradicional.

Segundo Branin e Case (1998), o sistema de publicação científica integra três principais componentes: os cientistas (autores da pesquisa); os editores; e os bibliotecários. Harnard (1995) chama a atenção para o fato de que os interesses de autores e editores são divergentes. Os primeiros desejam a difusão livre e 
rápida de seus trabalhos, para serem reconhecidos. Os últimos buscam obter benefícios financeiros, restringindo o acesso à informação a quem pode pagar.

Van de Sompel e Lagoze (2000) chamam especial atenção para a questão da denominada "crise dos periódicos". Em sua visão, ela se dá, primordialmente, nas bibliotecas de pesquisa, as quais não possuem fundos suficientes para manter as assinaturas dos principais títulos, visto que o valor destes se eleva, cada vez mais. Sobre a questão dos custos envolvidos na edição de periódicos científicos, King e Tenopir (1998) ressaltam quatro aspectos: (1) processamento de artigos; (2) impressão e distribuição; (3) processamento de outras matérias que não são artigos; (4) e serviços de apoio à publicação. De fato, um número variado de estudos reforça a questão dos altos custos das revistas científicas nas últimas décadas.

É neste contexto, portanto, que surgem os primeiros Arquivos Abertos. O arXiv foi o pioneiro das iniciativas, implementado em 1991, por Paul Ginsparg, de Los Alamos National Laboratory (LANL), Novo México, Estados Unidos da América (EUA), como repositório que abriga artigos de Física, Matemática e Ciência da Computação. Outros repositórios foram criados posteriormente em outros campos do conhecimento. Do mesmo modo, outras formas de publicação e acesso à pesquisa, como periódicos eletrônicos e repositórios institucionais, também foram desenvolvidas e passaram a adotar as especificações definidas pela Open Archives Initiative (Iniciativa dos Arquivos Abertos, OAI), isto é, padrões para garantir a interoperabilidade entre os sistemas (VAN DE SOMPEL; LAGOZE, 2000).

No que concerne às revistas eletrônicas, Lancaster (1995) considera que a primeira experiência se deu, em 1979, pelo Electronic Information Exchange System. No ano seguinte, a British Library financiou a Loughborough University para estabelecer um título experimental on-line na área de fatores humanos na Computação. Os primeiros experimentos não tiveram muito sucesso e foram descontinuados. Ainda segundo o autor, os periódicos científicos em suporte eletrônico apresentam muitas vantagens em relação ao formato impresso, como rapidez na publicação e no acesso. Mas, cabe lembrar que muitas pessoas ainda não têm acesso ao computador e à internet, e alguns acham incômodo ler na tela do computador.

De acordo com Stumpf (1996), a partir da década de 70, o uso do computador provocou avanços, viabilizando a melhoria da qualidade e incrementando a rapidez na editoração. O Projeto BLEND, desenvolvido nos anos 80, pela University of Birmingham e Loughborough University e financiado pela British Library, procurou avançar mais na produção dos periódicos. Visou não somente automatizar as etapas do processo, mas substituir, totalmente, a publicação impressa pela armazenagem eletrônica dos artigos e, em conseqüência, seu acesso.

Há, contudo, uma gama de questões que necessitam de maior discussão.. Harnard (1995), por exemplo, ressalta que, nas publicações eletrônicas, é possível uma economia de até $70 \%$, uma vez que não há custos com papel, impressão, marketing e distribuição para os títulos que são somente eletrônicos. Somente duas categorias de custo permanecem: avaliação e editoração. Moreno e Márdero Arellano (2005) reiteram que embora seja necessário um investimento 
inicial para mudar para uma versão eletrônica, ao longo do tempo os custos diminuem.

Analisando questões do periódico eletrônico, Mueller (2003) destaca problemas de confiança e de acesso, decorrentes dos hábitos da comunidade científica e dos interesses dos editores comerciais. Meadows (1999) destacara, também, que o suporte on-line pode parecer mais informal, dando a impressão de que o controle pode ser menos prudente do que o das publicações impressas no que se refere à qualidade da pesquisa. No entanto, diante do incremento de revistas eletrônicas com qualidade científica, ocorre conseqüente incremento na aceitação por parte dos cientistas (MUELLER, 2003).

O crescimento nas ocorrências de periódicos científicos eletrônicos fez surgir novas preocupações e iniciativas, resultantes das vantagens oferecidas pelas TIC. A principal iniciativa (e a mais polêmica), é o Movimento do Acesso Aberto (Open Access ou OA), discutido a seguir.

\subsection{Movimento do Acesso Aberto à literatura científica}

O Movimento do Acesso Aberto à literatura científica surgiu por conta de diversos fatores. Segundo Suber (2003), além da elevação do valor das revistas, é também relevante considerar as barreiras de permissão. Harnard et al. (2004) acrescentam a questão da perda do potencial impacto das pesquisas. Destacam que existem cerca de 24.000 periódicos com mecanismo de avaliação por pares no mundo, publicando, aproximadamente, 2,5 milhões de artigos por ano.

Em razão de barreiras impostas por custos cada vez mais altos, os usuários têm acesso cada vez mais limitado aos títulos científicos, perdendo-se muito do potencial impacto de artigos com acesso pago. $\mathrm{Na}$ medida em que o impacto é crucial para a carreira dos pesquisadores, pois mede o progresso e a produtividade da pesquisa e serve como meio para obter benefícios junto às "suas" universidades e às agências de fomento (HARNARD et al., 2004), quanto maior o impacto, mais benefícios para a ciência e comunidade científica. Por este motivo, é relevante o referido Movimento.

É importante lembrar que as primeiras ações em direção ao Acesso Aberto - Budapest Open Access Initiative (2002) e Bethesda Statement on Open Access Publishing (2003) - sinalizaram duas estratégias, ambas em conformidade com a Iniciativa dos Arquivos Abertos. Na primeira, alusiva ao auto-arquivamento, autores depositam num repositório de Acesso Aberto seus artigos já publicados em algum periódico referendado. Harnard et al. (2004) chamam esta estratégia de Via Verde, porquanto os editores dão "sinal verde" para o auto-arquivamento de artigos por parte dos autores. Na segunda, dos periódicos de Acesso Aberto, chamada por esses estudiosos de Via Dourada, os editores garantem o Acesso Aberto aos conteúdos das próprias revistas. O Acesso Aberto é, portanto, a disponibilidade livre e irrestrita, em meio eletrônico, da literatura que os pesquisadores entregam ao mundo sem esperar pagamento em retorno, incluindo tanto os preprints quanto os post-prints.

Um resultado importante de tais ações é a citado documento Bethesda Statement on Open Access Publishing (2003), que estabelece: 
(a) O autor e o detentor do copyright garantem a todos os usuários o direito livre, irrevogável, mundial e perpétuo de acesso aos seus trabalhos; licença para copiar, usar, distribuir, transmitir e exibir o trabalho publicamente; para fazer e distribuir trabalhos derivados, em qualquer meio digital para qualquer propósito responsável, sujeito à atribuição correta de autoria, assim como o direito de fazer um pequeno número de cópias para uso pessoal.

(b) Uma versão completa do trabalho e todos os materiais suplementares, incluindo uma cópia da permissão citada anteriormente, em formato eletrônico, devem ser depositados, logo após a publicação, em repositório mantido por uma instituição acadêmica, sociedade científica, agência governamental ou outra instituição que deseje permitir o Acesso Aberto.

Essas e outras iniciativas deram impulso ao Movimento do Acesso Aberto, causando certa pressão nas editoras que continuam detendo o copyright e impondo altos preços às assinaturas. A questão relevante, no entanto, que é o acesso e o conseqüente impacto das pesquisas, tem sido motivo de numerosos debates nos dias atuais. O aumento do impacto pode ser comprovado por estudos realizados nos últimos anos. Lawrence (2001), ao analisar artigos de Ciência da Computação, constata que ocorrem 336\% mais citações aos artigos disponíveis on-line em comparação com os artigos publicados off-line. Antelman (2004) verificou que, mesmo em disciplinas de diferentes áreas do conhecimento (Filosofia, Ciência Política, Engenharia Elétrica e Eletrônica, e Matemática), o impacto é maior para os artigos submetidos ao Acesso Aberto, apesar das diferenças que continuam a existir entre as disciplinas.

Um último, mas não menos importante aspecto sobre o Acesso Aberto e os periódicos científicos eletrônicos, é o surgimento de novos e diversificados modelos de negócios para as revistas assim disponíveis. Tais modelos, como os 10 propostos por Wilinsky (2006), surgem como alternativa ao padrão tradicional das editoras comerciais. A preocupação com tudo isto levou ao surgimento de iniciativas, entre as quais a criação do OJS, discutido a seguir.

De acordo com Meirelles (2006), os sistemas de gerenciamento de revistas eletrônicas surgiram como tentativa para organizar a informação da internet e administrar as atividades do processo editorial. Isto ocorreu devido ao Movimento de Acesso Aberto e à Iniciativa dos Arquivos Abertos. Fonseca et al (2004) destacam que os periódicos de Acesso Aberto são uma tendência cada vez mais crescente no ambiente científico. A escolha por um instrumento que automatiza o processo editorial, usando padrões e tecnologias baseados na filosofia do Acesso Aberto torna-se solução alternativa face à escassez de recursos. Além disto, estimula a democratização do acesso à informação, tornando o conteúdo disponível e favorecendo a interoperabilidade com provedores de serviço, nacionais e internacionais.

Segundo Márdero Arellano, Santos e Fonseca (2005), o OJS destaca-se entre os sistemas para edição e disseminação da produção científica de suporte 
ao Acesso Aberto. Trata-se de software com os elementos essenciais para a automação da editoração de periódicos científicos, desde a submissão e avaliação de um manuscrito até sua publicação e indexação. Como antes visto, em 2003, o lbict traduziu e customizou o OJS para a realidade brasileira, atribuindo-Ihe a designação de Sistema Eletrônico de Editoração de Revistas. O SEER estava sendo adotado, em março de 2008, por mais de 300 títulos e, decerto, hoje, este número é bem maior. O SEER utiliza o protocolo OAI para o intercâmbio de metadados. Além disto, possui suporte para mecanismos de preservação do conteúdo (a exemplo de Lots of Copies Keep Stuff Safe ou LOCKSS), sendo, assim, ferramenta de apoio à pesquisa.

Observa-se, neste contexto, que as facilidades e, mais especificamente, a amigabilidade de plataformas como o SEER têm provocado seu uso de modo quase indiscriminado. Isso porque a liberdade no uso parece ter dado origem a uma variedade de produtos nem sempre comprometidos com a qualidade requerida de um periódico científico.

\subsection{Qualidade de periódicos científicos}

A análise da literatura sobre qualidade de periódicos científicos permite considerar que ela pode ser avaliada com foco no processo ou no resultado. $\mathrm{Na}$ primeira situação, consideram-se fatores relacionados com a gestão editorial, tais como formação e expertise da equipe editorial (editores, corpo e conselho editoriais), regras de submissão e de avaliação de manuscritos, prazos de avaliação e de disponibilização de artigos aprovados, dentre outros itens. $\mathrm{Na}$ avaliação com foco no resultado, importa saber o nível de impacto que artigos publicados em determinado título exercem sobre a comunidade científica e, portanto, em que medida contribuem para o fortalecimento de determinada área. Nesta linha de pensamento, quanto mais os artigos de certa revista são citados por outros autores, maior seu nível de impacto.

Tais metodologias não são excludentes, uma vez que um processo editorial adequado certamente contribuirá para a qualidade dos artigos publicados: quanto maior o nível de qualidade destes, maior a probabilidade de o periódico alcançar um alto nível de impacto. Há outras visões, como, por exemplo, a de Trzesniak (2006), que vincula a qualidade de um periódico científico ao atendimento de três pré-requisitos. O primeiro, proporcionar aos pesquisadores que o consultam conhecimentos novos e de relevância em seu campo de atuação. O segundo, divulgar esses conhecimentos de forma ágil. Finalmente, ser perene. No caso da avaliação com foco no processo, cabe citar, aqui, dois trabalhos relevantes relacionados à temática.

Ferreira (2005), tomando como base algumas iniciativas como a Scientific Electronic Library Online (SciELO); o Sistema Regional de Información en Línea para Revistas Científicas de América Latina, el Caribe, España y Portugal (Latindex) e o ISCU Press, identificou os principais critérios de qualidade de revistas científicas, em meio impresso e eletrônico. A autora agrupou os parâmetros segundo quatro aspectos. O primeiro diz respeito às características básicas das revistas. O segundo, aos aspectos referentes à apresentação formal. 
O terceiro refere-se à tipologia de conteúdos e autoria. O último, aos aspectos de gestão e de política editorial da revista.

Krzyzanowski e Ferreira (1998), por sua vez, estudaram periódicos científicos e técnicos brasileiros avaliados por agências de fomento, tais como: Fundação de Amparo à Pesquisa do Estado de São Paulo (FAPESP), Conselho Nacional de Desenvolvimento Científico e Tecnológico (CNPq) e Financiadora de Estudos e Projetos (Finep). Analisaram critérios sobre mérito e forma. Para a avaliação de mérito, convocaram pesquisadores da FAPESP de cada área do conhecimento a fim de que classificassem as publicações de acordo com sua relevância. Para tanto, os profissionais julgaram: qualidade da publicação (artigos, corpo editorial, arbitragem); natureza do órgão publicador; e indexação.

Para a avaliação de forma, as autoras avaliaram os últimos três fascículos de cada título quanto à(s): normalização, duração, periodicidade, indexação de títulos em bases de dados internacionais, formas de distribuição, existência (ou não) de coleção nas bibliotecas-base do Sistema Comut, colaboração de autores e divisão de conteúdo. Concluíram, por fim, que as agências financiadoras poderiam instituir um método de avaliação de periódicos mais abrangente e uniforme, tal como o de conteúdo e forma, de modo a realizar julgamento mais preciso. Sugeriram, também, que as agências mantenham estável o subsídio dos títulos classificados como prioritários pertencentes a institutos de pesquisa, instituições de ensino e sociedades científicas.

No caso da avaliação com foco no resultado, é preciso fixar o nível de impacto dos periódicos, o que requer organização e manutenção de bases de dados específicas, atividade até então realizada, primordialmente, em paises desenvolvidos. Experiência recente com nações da América Latina é o Portal SciELO, que pode contribuir para a geração de indicadores de impacto de títulos de revistas dos países envolvidos.

Calvert e Zengzhi (2001) acreditam que alguns critérios avaliados em periódicos são basicamente extrínsecos. Exemplos deste tipo de parâmetros são: composição, reputação do periódico, afiliação e reputação do editor responsável, Conselho Editorial, política de avaliação dos artigos e percepção do periódico. No entanto, poucos dos envolvidos com a publicação de periódicos científicos os considerariam importantes para a avaliação de sua qualidade. Ao invés disso, focariam o conteúdo do título e a qualidade dos artigos publicados.

Para a avaliação de qualidade dos artigos é comum a utilização da bibliometria. Um exemplo deste tipo de estudo realizado recentemente, no Brasil, é o de Machado-da-Silva et al. (2008), que avaliaram revistas científicas brasileiras em Administração, utilizando o fator de impacto relacionado com a classificação dos títulos no Sistema Qualis da Coordenação de Aperfeiçoamento de Pessoal de Nível Superior (Capes). Analisaram, durante 2005 a 2007, 21 periódicos e anais do Encontro Nacional da Associação Nacional de PósGraduação e Pesquisa em Administração (EnANPAD). Agruparam os títulos em três blocos: "A" Nacional Antigos (nota de avaliação "A", há algum tempo); "A" Nacional Recentes (nota de avaliação "A", em 2007); "B" Nacional. Os autores verificaram que as citações e o fator de impacto são maiores no primeiro grupo. Quanto aos dois outros agrupamentos, não houve diferença significativa entre os fatores de impacto. Constataram, ainda, que inexiste influência expressiva das 
autocitações no cálculo desse fator. Por fim, a pesquisa inferiu que o fator de impacto é um critério viável e relevante na avaliação de periódicos. Porém, isto não significa que somente ele deva ser utilizado. Reconhecê-lo como relevante significa também entender que ele pode ser adotado em conjunto com outros.

Apesar dos métodos bibliométricos serem os mais comuns nos países desenvolvidos, sobretudo, por conta da atuação do Institute for Scientific Information (ISI) e do Science Citation Index (SCI), Valerio (1994) observou que a comunidade de países terceiro-mundistas questiona amplamente estes tipos de estudo. Isto se dá por conta da baixa representatividade de sua produção científica nos serviços de indexação e de resumos internacionais, sendo inviável, pois, recorrer a esse método como forma de medição da produção dessas nações.

No entanto, Krzyzanowski e Ferreira (1998) ressaltam que os principais problemas da produção brasileira referem-se à limitação do uso da língua portuguesa nos países estrangeiros e à originalidade e / ou inovação incipiente dos artigos publicados. Por tais motivos, o padrão de qualidade dos periódicos cai, dificultando o alcance da produção brasileira à comunidade científica internacional, e impossibilitando, também, a indexação dos títulos e / ou artigos em importantes bases de dados, índices e bibliografias, tal como o $\mathrm{SCl}$.

Como se observa, a inserção crescente das TIC no ambiente da pesquisa provocou significativos impactos no sistema de comunicação científica. Em especial, cientistas e pesquisadores passaram a utilizar o meio eletrônico para publicar seus resultados. Por sua vez, isto assegurou a expansão dos periódicos científicos eletrônicos. E mais que isto, as facilidades da comunicação eletrônica contribuíram para a identificação de alternativas à "crise dos periódicos", o que contribuiu para o surgimento do Movimento do Acesso Aberto. Neste contexto, ferramentas que facilitam tanto o processo de editoração de periódicos quanto a própria gestão de sua publicação, como o SEER, têm colaborado para fortalecer o Movimento. No entanto, liberdade e facilidade de uso podem levar a não observância de questões relevantes sobre a qualidade do periódico científico. São estas, portanto, as questões que norteiam o presente estudo.

\section{METODOLOGIA}

Diante do objetivo explicitado de analisar a qualidade dos periódicos científicos eletrônicos brasileiros criados por meio do SEER, buscou-se, na literatura, os principais critérios para avaliar a qualidade, selecionando-se os mais relevantes. Optou-se por indicadores de qualidade de processo, que vêm sendo adotados por agências brasileiras de fomento ao ensino e à pesquisa.

Trata-se de pesquisa de natureza descritiva, que utilizou o método de levantamento, adotando abordagem quantitativa. Os dados foram coletados com base na verificação da presença ou não dos critérios selecionados para análise, nas páginas eletrônicas dos títulos e nos curricula vitae Lattes dos autores e membros do Conselho Editorial, disponíveis na página eletrônica do CNPq. Na inexistência de currículo Lattes, foram recuperadas informações sobre os profissionais em mecanismos de busca, como a página Google e outras assemelhadas. 
O universo foi constituído por periódicos científicos brasileiros que utilizam - SEER e possuíam, no momento da pesquisa, páginas acessíveis por meio do site do Ibict. Foi possível identificar o total de 303 revistas, em março de 2008, época da coleta de dados. Como estudo-piloto, a amostra utilizada compreendeu $5 \%$ do universo, distribuídos em cada uma das grandes áreas do conhecimento. De acordo com a ordem exposta no site do lbict, compilou-se uma lista com todos os periódicos de cada área, numerados seqüencialmente. Para a amostra, selecionaram-se, aleatoriamente, vários números presentes numa tabela de números aleatórios. No cálculo do número de revistas para cada área $(5 \%)$, arredondaram-se para cima todas as frações obtidas, considerando-se o mínimo de um título por área. Desta forma, a amostra foi composta por 16 periódicos no total.

O instrumento utilizado para obter os dados necessários ao estudo foi uma lista de verificação composta de duas partes. Na primeira, designada para captação e análise de informações referentes aos autores de artigos publicados e aos membros do Conselho Editorial de cada periódico, se inseriu o total de pessoas que contemplavam o critério então avaliado. A segunda foi designada para avaliação do periódico em si, ou seja, ausência ou presença de cada critério estudado.

\subsection{Variáveis analisadas}

As variáveis estudadas compreendem um conjunto de critérios considerados relevantes para atestar a qualidade de um periódico científico. Tais critérios, identificados na literatura, particularmente no trabalho de Ferreira (2005), compreendem fatores de qualidade das revistas, ora indicados.

a. Conselho Editorial e autores (foram analisados os dados dos autores do último fascículo publicado de cada periódico)

i. Afiliação - refere-se ao número de pessoas com vínculo à instituição responsável pela editoração do periódico. Utilizou-se a expressão "não se aplica", quando não foi possível identificar a afiliação.

ii. Formação / nível de titulação de membros de conselhos editoriais e de autores de artigos - adota-se a seguinte escala: graduação e especialização; mestrado; doutorado. Utilizou-se a expressão "não se aplica", quando não foi possível identificar a formação ou quando esta era inferior à graduação.

iii. Produtividade - considera-se as pessoas com, no mínimo, dois artigos publicados em periódicos, no decorrer de 2007. Utilizou-se a expressão "não se aplica", quando não foi possível identificar a produtividade e, também, nos casos de currículos Lattes desatualizados.

b. Regras de submissão de artigos 
i. Percentual de trabalhos inéditos. Clareza na definição do percentual mínimo de trabalhos inéditos decorrentes de pesquisa e de outros trabalhos, tais como, revisões de literatura, etc. Utilizou-se como padrão o mínimo de $40 \%$ de trabalhos inéditos.

ii. Critérios de formatação e normalização. Clareza em sua especificação.

c. Arbitragem por pares

i. Procedimentos de avaliação. Clareza dos dados quanto aos procedimentos de avaliação dos manuscritos.

ii. Datas do processo de avaliação. Clareza dos dados a respeito de datas do processo de avaliação, com o mínimo das datas de submissão e de aprovação.

\section{RESULTADOS E DISCUSSÃO}

A metodologia adotada permitiu a coleta de dados necessários à consecução dos objetivos propostos, de modo que, aqui, estão descritos e discutidos os resultados obtidos, à luz da literatura analisada e de observações empíricas das autoras.

\subsection{Resultados sobre Conselho Editorial}

Em relação ao Conselho Editorial, constatou-se que, no caso de afiliação, de um total de 168 membros pertencentes às 16 revistas estudadas, 55\% são afiliados às instituições responsáveis pelos respectivos periódicos e há $45 \%$ não afiliados. Quanto à formação / ao nível de titulação: $85 \%$ possuem doutorado; $11 \%$, mestrado; $2 \%$, graduação; e dos demais $2 \%$, não foi possível identificar o nível de escolaridade. No que diz respeito à produtividade, a maioria $(53,6 \%)$ dos membros do Conselho é produtiva, com, pelo menos, dois trabalhos publicados no último ano.

No decorrer da pesquisa, vários periódicos foram substituídos por não descreverem, em suas páginas, a composição do Conselho Editorial. É importante notar, no entanto, que, como Ferreira (2005, p. 272) reforça, é "essencial a menção clara e inequívoca de um Conselho Editorial ou um responsável científico pela revista. A composição do Conselho deve ser pública". Tal critério é também especificado por Trzesniak (2006), em seu estudo sobre periódicos em Educação, e, também, em SciELO (2004), como um dos critérios para admissão no Portal. Mesmo assim, foram necessárias várias tentativas para compor uma amostra que o apresentasse explicitamente.

Além do mais, as estatísticas sobre o Conselho Editorial mostram predominância de profissionais pertencentes à entidade do próprio periódico. Tal 
fator é prejudicial à qualidade. Segundo Ferreira (2005), revela endogenia. Esta é caracterizada por Valerio (1994), como a presença, na publicação, de quantidade significativa de avaliadores, autores ou membros do Conselho Editorial pertencentes à instituição editora. Tal fato não é benéfico para a ciência, uma vez que se tem um ponto de vista unilateral dos avaliadores. $E$ mais, nem 0 intercâmbio é viabilizado nem tampouco a renovação de idéias. Ao contrário, ocorrem estagnação e perpetuação das mesmas idéias, das mesmas pessoas e / ou dos mesmos grupos.

A diversidade dos membros do Conselho Editorial (nacionalmente e internacionalmente) e sua qualificação constituem um dos critérios de avaliação de periódicos. É ele utilizado, no mínimo, por quatro instituições. A primeira, Thomson Scientific (2009), responsável pelo ISI e SCI, além de outras iniciativas. A segunda, o Portal SciELO (2004). A terceira, a Associação Brasileira de Editores Científicos (ABEC, 2009), que o utiliza para seleção de revistas científicas eletrônicas com fins de financiamento. Finalmente, a Capes, em seu sistema Qualis, na avaliação de títulos das diferentes áreas. De forma similar, foram encontrados critérios semelhantes no já mencionado estudo de Krzyzanowski e Ferreira (1998); no trabalho de Ali e Young e Ali (1996), com a elaboração de lista de verificação de aspectos de qualidade para decisões de financiamento; e na mencionada pesquisa de Trzesniak (2006).

Se a formação da maior parte dos membros dos conselhos dos periódicos pesquisados é considerada adequada do ponto de vista de titulação (predomina o doutorado), vale comentar que, quase metade dos participantes dos conselhos editoriais não atinge o mínimo de dois trabalhos publicados em periódicos, por ano. Isto pode significar envolvimento incipiente com atividades científicas e de pesquisa, elemento imprescindível a membros do Conselho Editorial, como responsável por manter o nível de qualidade dos títulos.

\subsection{Resultados sobre autores}

Quanto aos autores (do último fascículo publicado, 373 no total), no item afiliação, eis os dados: $62,2 \%$ são externos à instituição mantenedora do periódico; 34,3\% são internos. No que se refere à titulação: $49 \%$ dos autores possuem doutorado; 24\%, mestrado; 17\%, graduação ou especialização; para o percentual de $10 \%$, não foi possível identificar o nível de formação. Sobre a produtividade, $43 \%$ são produtivos, com pelo menos dois trabalhos publicados no último ano.

Tais resultados revelam que o percentual de autores externos não alcançou o predomínio absoluto (70\%), que seria o mínimo recomendável por Ferreira (2005) para evitar a endogenia. Concordando com a autora, Trzesniak (2006) recomenda que mais de $60 \%$ dos artigos publicados sejam de autores de instituições diferentes da que edita o periódico, excluídos os autores estrangeiros. No caso destes últimos, é recomendada a publicação de, no mínimo, 10\% de artigos, durante os três últimos anos. A Thomson Scientific (2009) estabelece como critério, de maneira mais geral, a diversidade internacional entre os autores das revistas. E a Capes, em sua avaliação, observa se há nos artigos publicados a predominância de autores externos à instituição editora (BARBALHO, 2005). 
No que diz respeito à formação, apesar de quase metade dos autores possuírem doutorado, $10 \%$ ainda não possuem graduação completa e mais da metade não alcança o nível mínimo de produtividade. Ferreira (2005, p. 273) sugere que se deve dar "prioridade [a] autores com maior maturidade científica e [a] trabalhos com impacto sobre o campo científico da revista". Esta sugestão é criticável porque pode significar direcionamento e preferência por determinado segmento de autores. Além disto, se a revista estabelecer como política editorial prioridade para autores mais maduros estaria criando uma barreira aos entrantes e, conseqüentemente, à oxigenação e à evolução da ciência. Além do mais, o fato de um autor ser sênior não significa, necessariamente, que seu artigo terá qualidade superior à de um artigo de autoria de um pesquisador iniciante. Isto é, a senioridade não garante per se a qualidade do trabalho.

Calvert e Zengzhi (2001) corroboram esta idéia, ao ressaltarem que, apesar de editores de periódicos ficarem satisfeitos em publicar artigos de autores com boa reputação precisam se conscientizar de que muitos artigos serão de autores cujos nomes não atraem nenhuma atenção particular. A avaliação de qualidade dos artigos, portanto, deve ser baseada no próprio mérito, o qual se refere a oito fatores, nomeadamente: originalidade e inovação; reconhecimento dos trabalhos anteriores; relevância para o corpo de conhecimentos da área; objetividade; escrita clara; qualidade dos argumentos; implicações teóricas e práticas; estar de acordo com os objetivos editoriais do periódico.

\subsection{Resultados sobre os periódicos estudados}

\section{Regras de submissão de artigos}

Com relação às regras de submissão de artigos, os resultados mostram que: nenhum dos periódicos selecionados indica qual deve ser o percentual mínimo de trabalhos decorrentes de pesquisa; $87,5 \%$ especificam, com clareza, a formatação e a normalização a serem seguidas para a apresentação dos trabalhos; $43,75 \%$ trazem em sua página explicação satisfatória a respeito da avaliação; $50 \%$ especificam claramente nos artigos aceitos para publicação as datas de submissão e aceitação.

Atesta-se, diante dos resultados obtidos, a carência de qualidade nas regras de submissão de originais. O trabalho de Krzyzanowski e Ferreira (1998) e os critérios da ABEC (2008) não afirmam que o periódico deve apresentar o percentual em seu escopo. Entretanto, afirmam ser necessário que os títulos publiquem, no mínimo, $50 \%$ de artigos originais provenientes de pesquisas. Em contraposição, a grande maioria das revistas $(87,5 \%)$ define de forma satisfatória as regras de formatação e de normalização para os autores que desejem submeter seus originais. Este parâmetro é considerado na avaliação de ABEC (2008); CAPES; e SciELO (2004).

\section{Arbitragem por pares}

Os dados obtidos revelam que ainda falta a $56,24 \%$ dos periódicos uma explicação consistente e concisa em suas respectivas páginas eletrônicas sobre a 
avaliação por pares, fator básico para Krzyzanowski e Ferreira (1998) e SciELO (2004). Um título de qualidade deve especificar a metodologia adotada para avaliação e aprovação dos artigos a fim de que os autores possam tomar conhecimento do que é considerado essencial para que os artigos sejam aceitos para publicação. No entanto, somente metade deles indica, nos textos publicados, as datas do processo de arbitragem, quando foi recebido, aceito para publicação e publicado. O ideal seria que todos explicitassem, no mínimo, a data de recebimento do original e a data de aceitação. Tal fator consta dos critérios de avaliação de ABEC (2008); SciELO (2004); e Trzesniak (2006).

\section{CONCLUSÃO}

Reitera-se que o objetivo principal do estudo foi, com base na literatura especializada da Ciência da Informação, avaliar a qualidade de periódicos científicos brasileiros que utilizam o SEER. A partir de análise quantitativa, chegou-se a resultados relevantes que podem ser levados em conta por editores de revistas eletrônicas, para que estas atinjam qualidade e sejam, então, consideradas, de fato, científicas. Somente assim, conquistarão maior visibilidade e aceitação no meio acadêmico.

Afinal, os dados obtidos permitiram verificar que, no geral, os títulos que compõem a amostra não cumprem os requisitos mínimos de qualidade para que possam ser categorizados como científicos. Isto é, não correspondem às expectativas da comunidade acadêmica no que concerne à observação de tais critérios. É certo que a pesquisa avaliou somente uma amostra de $5 \%$ dos periódicos eletrônicos que utilizam o SEER, e uma avaliação mais completa exigiria avaliar todos os títulos ou trabalhar com amostra mais significativa. $\mathrm{Na}$ realidade, os resultados apontam a necessidade de abordagem longitudinal que permita observar a evolução ou não da qualidade desse conjunto de títulos brasileiros. No decorrer da pesquisa, observou-se, em vários periódicos (além dos que compunham a amostra), o não cumprimento de alguns dos critérios de qualidade, o que ratifica a premência de avaliação mais ampla.

Além disto, existem diversos periódicos eletrônicos brasileiros que não utilizam o SEER para sua editoração, e que também necessitam de avaliação no que concerne à qualidade. Cabe acrescentar que, devido à variedade na apresentação dos periódicos eletrônicos, a Capes aconselhou aos editores que padronizem as páginas dos periódicos utilizando como referenciais o Portal SciELO e o SEER.

Também seria interessante realizar estudo comparando títulos impressos e eletrônicos. Desta maneira, seria possível constatar se há diferenças na qualidade apresentada por ambos os grupos. Além do mais, novos estudos envolvendo qualidade fazem com que autores, editores e pesquisadores atentem mais para esta questão e a considerem na hora de submeter um artigo, gerenciar e criar um periódico eletrônico e participar da avaliação de artigos. Afinal, como se pode depreender da discussão apresentada, o atendimento de quesitos de qualidade incide diretamente na visibilidade dos periódicos, bem como em seu nível de prestígio e de seus editores. 


\section{REFERÊNCIAS}

ALBERTS, B. Engaging in a worldwide transformation: our responsibility as scientists for the provision of global public goods. 29 Apr. 2002. Disponível em: <http:// www.nasonline.org/site/DocServer/speech2002.pdf?doclD=121>. Acesso em: 24 nov. 2007.

ALI, S. N.; YOUNG, H. C.; ALI, N. M. Determining the quality of publications and research for tenure or promotion decisions: a preliminary checklist to assit. Library Review, [S. I.], v. 45, n. 1, p. 39-53, 1996.

ANTELMAN, K. Do open-access articles have a greater research impact? College \& Research Libraries, [S. I.], v. 65, n. 5, p. 372-382, Sept. 2004.

ASSOCIAÇÃO BRASILEIRA DE EDITORES CIENTÍFICOS (ABEC). Critérios para seleção de revistas científicas eletrônicas: CNPq / Finep. Disponível em: $<$ http:// www.liber.ufpe.br/abec/arquivos/CriteriosElet.pdf>. Acesso em: $15 \mathrm{fev}$. 2009.

BARBALHO, C. R. S. Periódicos científicos em formato eletrônico: elementos para sua avaliação. In: CONGRESSO BRASILEIRO DE CIÊNCIAS DA COMUNICAÇÃO, 28., 2005, Rio de Janeiro. Anais... São Paulo: Intercom, 2005. Disponível em: <http://www. intercom.org.br/papers/nacionais/2005/resumos/R0986-1.pdf>. Acesso em: 5 jan. 2009.

BETHESDA Statement on Open Access Publishing. 2003. Disponível em: <http://www. earlham.edu/ peters/fos/bethesda.htm>. Acesso em: 11 nov. 2009.

BRANIN, J. J.; CASE, M. Reforming scholarly publishing in the sciences: a librarian perspective. Notices of the American Mathematical Society, [S. I.], v. 45, n. 4, p. 475-486, Apr. 1998.

BUDAPEST Open Access Initiative. 2002. Disponível em: <http://www.soros. org/ openaccess>. Acesso em: 2 out. 2009.

CALVERT, P. J.; ZENGZHI, S. Quality versus quantity: contradictions in LIS journal publishing in China. Library Management, [S. I.], v. 22, n. 4 / 5, p. 205-211, 2001.

COSTA, S. M. S. The impact of computer usage on scholarly communication amongst academic social scientists. 1999. $291 \mathrm{f}$. Doctoral Thesis - Departament of information Science, Loughbourough University, Loughbourough. 1999.

O novo papel das tecnologias digitais na comunicação científica. In: MARCONDES, Carlos et al. (Org.). Bibliotecas digitais: saberes e práticas. 2. ed. Salvador: Edufba; Brasília, DF: Ibict, 2006. p. 165-183. 
FERREIRA, S. M. S. P. Critérios de qualidade para as revistas científicas em comunicação. In: FERREIRA, S. M. S. P.; TARGINO, M. das G. (Org.). Preparação de revistas científicas: teoria e prática. São Paulo: Reichmann \& Autores, 2005. p. 269-293.

FONSECA, R. M. S. da et al. Electronic System for Journal Publishing (SEER). In: ICCC INTERNATIONAL CONFERENCE ON ELECTRONIC PUBLISHING, 8., 2004, Brasília, DF. Proceedings... Brasília, DF: CID / UnB, 2004. p. 226-236.

GARVEY, W. D., GRIFFITH, B. C. Communication and information process within scientific disciplines, empirical findings for psychology. In: GARVEY, W. D. Communication: the essence of science; facilitating information among librarians, scientists, engineers and students. Oxford: Pergamon, 1979. p.127-147.

HARNARD, S. Electronic scholarly publication: quo vadis? Serials Review, Greenwich, v. 21, n. 1, p. 70-72, 1995.

HARNARD, S. et al. The access / impact problem and the green and gold roads to Open Access. 2004. Disponível em: <http://eprints.ecs.soton.ac.uk/9939/1/impact. html>. Acesso em: 24 set. 2009.

HURD, J. M. Models of scientific communication systems. In: CRAWFORD, S. Y.; HURD, J. M.; WELLER, A. C. (Ed.). From print to electronic: the tranformation of scientific communication. Medford: Information Today, 1996.

KING, D. W.; TENOPIR, C. A publicação de revistas eletrônicas: economia da produção, distribuição e uso. Ciência da Informação, Brasília, DF, v. 27, n. 2, p. 176-182, maio / ago. 1998.

KRZYZANOWSKI, R. F.; FERREIRA, M. C. G. Avaliação de periódicos científicos e técnicos brasileiros. Ciência da Informação, Brasília, DF, v. 27, n. 2, p. 165-175, maio / ago. 1998.

LAGOZE, C.; VAN DE SOMPEL, H. The Open Archives Iniciative: building a lowbarrier interoperability framework. 2001. Disponível em: <http://www.openarchives.org/ documents/jcdl2001-oai.pdf>. Acesso em: 15 out. 2009.

LANCASTER, F. W. The evolution of electronic publishing. Library Trends, Champaign, v. 43, n. 4, p.713-740, spring 1995.

LAWRENCE, S. Free on-line availability substantially increases a paper's impact. Nature, [S. I.], v. 411, n. 521, May 2001.

MACHADO-DA-SILVA, C. L. et al. Periódicos brasileiros de Administração: análise bibliométrica de impacto no triênio 2005-2007. RAC-Eletrônica, Curitiba, v. 2, n. 3, p. 351-373, set. / dez. 2008. 
MÁRDERO ARELLANO, M. Á.; SANTOS, R. dos; FONSECA, R. da. SEER: disseminação de um sistema eletrônico para editoração de revistas científicas no Brasil. Arquivistica.net, Rio de Janeiro, v. 1, n. 2, p. 75-82, jul. / dez. 2005.

MEADOWS, A. J. A comunicação científica. Brasília, DF: Briquet Lemos Livros, 1999.

MEIRELLES, R. F. O Sistema Eletrônico de Editoração de Revistas (SEER) e sua adoção em periódicos brasileiros. Arquivistica.net, Rio de Janeiro, v. 2, n. 2, p. 197-207, ago. / dez. 2006.

MORENO, F. P.; MÁRDERO ARELLANO, M. Á. Publicação científica em arquivos de Acesso Aberto. Arquivística.net, Rio de Janeiro, v. 1, n. 1, p. 76-86, jan. / jun. 2005.

MUELLER, S. P. M. O periódico científico. In: CAMPELLO, B. S.; CÉNDON, B. V.; KREMER, J. M. (Org.). Fontes de informação para pesquisadores e profissionais. Belo Horizonte: UFMG, 2003. p. 73-96.

SCIENTIFIC ELECTRONIC LIBRARY ONLINE (SciELO). Critérios SciELO Brasil: critérios, política e procedimentos para a admissão e a permanência de periódicos científicos na coleção SciELO Brasil. 2004. Disponível em: <http://www.scielo.br/criteria / scielo_brasil_pt.html>. Acesso em: 18 dez. 2009.

STUMPF, I. R. C. Passado e futuro das revistas científicas. Ciência da Informação, Brasília, DF, v. 25, n. 3, p. 383-386, 1996.

SUBER, P. Removing barriers to research: an introduction to Open Access for librarians. College and Research Libraries News, [S. I.], v. 64, n. 2, Feb. 2003.

TENOPIR, C.; KING, D. W. A importância dos periódicos para os trabalhos científicos. Revista de Biblioteconomia de Brasília, Brasília, DF, v. 25, n. 1, jan. / jun. 2001.

THOMSON SCIENTIFIC. The Thomson Scientific journal selection process. Disponível em: <http://www.thomsonreuters.com/business_units/scientific/free/ essays/ journalselection>. Acesso em: 15 fev. 2009.

TRZESNIAK, P. As dimensões da qualidade dos periódicos científicos e sua presença como instrumento da área da educação. Revista Brasileira de Educação, São Paulo, v. 11, n. 32, p. 346-361, maio / ago. 2006.

VALERIO, P. M. Espelho da ciência: avaliação do programa setorial de publicações em ciência e tecnologia da Finep. Rio de Janeiro: Finep, 1994.

VAN DE SOMPEL, H.; LAGOZE, C. The Santa Fe convention of the Open Archives Iniciative. D-lib Magazine, v. 6, n. 2, Feb. 2000. Disponível em: <http://www.dlib.org/ dlib/february00/vandesompel-oai/02vandesompel-oai.html>. Acesso em: 24 out. 2009. 
WILINSKY, J. Ten flavors of Open Access. In: The access principle: the case of Open Access to research and scholarship. London: The MIT Press, 2006. p. 211-216.

\title{
Title
}

The quality of Brazilian scientific and scholarly journals that use the Open Journal System (OJS).

\begin{abstract}
This study aimed to assess whether Brazilian journals that use the Open Journal System (OJS) for publishing comply with quality requirements necessary to scientific journals. The universe of the research was comprised of 303 titles, from which a stratified random sample of 16 journals (5\% of the total) was analyzed. The analysis consisted of the assessment of four aspects, namely, educational grade of the editorial board, editorial policy, editorial process and authors' profile. It was possible to conclude that, in general, these journals observe only partially the quality requirements usually indicated for a journal to be considered scientific.
\end{abstract}

\section{Keywords}

Scholarly and scientific electronic journals. Open Access to scientific literature. Open Journal System (OJS). Journals quality.

\section{Título}

La calidad de las revistas brasileñas que utilizan el Sistema Electrónico de Edición de Revistas (SEER).

\section{Resumen}

El estudio pretende evaluar si las revistas brasileñas que utilizan el Sistema Electrónico de Edición de Revistas (SEER) cumplen los requisitos de calidad necesarios para publicaciones científicos. El universo de la investigación consistió en 303 títulos, de los cuales se analizó una muestra aleatoria estratificada de 16 de ellos ( $5 \%$ del total). Se analizaron los datos sobre la formación de los comités editoriales, las políticas editoriales y el proceso de edición, así como el perfil de los autores. La conclusión general es que los títulos estudiados sólo atienden en parte los requisitos de calidad generalmente indicados para que una revista sea considerada científica.

\section{Palabras clave}

Revista científica electrónica. Acceso Abierto a la Literatura Científica. Sistema Electrónico de Edición de Revistas (SEER). Calidad de revistas.

Recebido em: 23/07/2010

Aceito em: 04/11/2010 